\title{
Dinámicas residenciales de la inmigración latinoamericana en las metrópolis de Barcelona y Madrid: cambios de tendencias durante la expansión, la crisis y la poscrisis*
}

\author{
Jenniffer Thiers-Quintana \\ Fernando Gil-Alonso \\ Universitat de Barcelona. Departamento de Geografía \\ jthiers@ub.edu \\ fgil@ub.edu
}

Recibido: enero de 2019

Aceptado: abril de 2019

Publicado: septiembre de 2019

\section{Resumen}

El artículo analiza las pautas residenciales y migratorias de la población de origen latinoamericano durante el período 2000-2017 en las áreas urbanas funcionales de Barcelona y Madrid, divididas en coronas de municipios en función de la distancia a la ciudad central. Utilizando datos del Padrón continuo y de la Estadística de variaciones residenciales (INE), la investigación estudia cómo responden estos fenómenos a las variaciones del ciclo económico, por eso se divide el período en tres fases desiguales: expansión económica (2000-2008), crisis (2009-2014) y poscrisis (2015-2017). Los resultados muestran que la tendencia hacia la suburbanización de esta población en ambas áreas urbanas durante la fase de crecimiento económico se frenó con la crisis, pero que se ha reactivado durante la poscrisis; y que, sin embargo, hay un aumento de su concentración en ambas ciudades centrales en los últimos años, debido a la reactivación de la inmigración latinoamericana.

Palabras clave: población latinoamericana; pautas residenciales; migraciones; áreas metropolitanas; Barcelona; Madrid; España

* Este texto forma parte de la tesis doctoral de Jenniffer Thiers Quintana y se enmarca en el proyecto $\mathrm{I}+\mathrm{D}+\mathrm{I}$ Nuevas movilidades y reconfiguración sociorresidencial en la poscrisis: consecuencias socioeconómicas y demográficas en las áreas urbanas españolas (RTI2018-095667-B-I00), dirigido por la Dra. Cristina López Villanueva y el Dr. Fernando Gil Alonso, y financiado por la Agencia Estatal de Investigación y el Fondo Europeo de Desarrollo Regional (AEI/ FEDER, UE). 
Resum. Dinàmiques residencials de la immigració llatinoamericana a les metròpolis de Barcelona i Madrid: canvis de tendències durant l'expansió, la crisi i la postcrisi

L'article analitza les pautes residencials i migratòries de la població d'origen llatinoamericà durant el període 2000-2017 a les àrees urbanes funcionals de Barcelona i Madrid, dividides en corones de municipis en funció de la distància a la ciutat central. Utilitzant dades del Padró continu i de l'Estadística de variacions residencials (INE), aquest treball estudia com responen aquests fenòmens a les variacions del cicle econòmic, per això es divideix el període analitzat en tres fases desiguals: expansió econòmica (2000-2008), crisi (2009-2014) i postcrisi (2015-2017). Els resultats mostren que la tendència cap a la suburbanització d'aquesta població en les dues àrees urbanes durant la fase de creixement econòmic es va frenar amb la crisi, però que s'ha reactivat durant la postcrisi. N'hi ha, però, un augment de la concentració a les dues ciutats centrals en els últims anys, a causa de la reactivació de la immigració llatinoamericana.

Paraules clau: població llatinoamericana; pautes residencials; migracions; àrees metropolitanes; Barcelona; Madrid; Espanya

Résumé. Dynamique résidentielle de l'immigration latino-américaine dans les régions urbaines de Barcelone et Madrid: évolution des tendances au cours des périodes d'expansion économique, de crise et de post-crise

L'article analyse le peuplement territorial et les migrations de la population d'origine latinoaméricaine de 2000 à 2017 dans les zones urbaines fonctionnelles de Barcelone et de Madrid, divisées en couronnes de municipalités en fonction de leur distance au centre-ville. En utilisant les données du registre continu et de la statistique des variations résidentielles (INE), cette recherche étudie la manière dont ces phénomènes répondent aux changements du cycle économique. C'est pourquoi la période est divisée en trois phases inégales : expansion économique (2000-2008), crise (2009-2014) et post-crise (2015-2017). Les résultats montrent que la crise a mis fin à la tendance à la suburbanisation des populations latino-américaines dans les deux zones urbaines, mais qu'elle a été réactivée au cours de la période post-crise. Cependant, la concentration de la population latino-américaine dans les deux villes centrales s'est accrue ces dernières années, en raison de la réactivation de l'immigration originaire des pays latino-américains.

Mots-clés: population latino-américaine; comportement résidentiel; migrations; zones métropolitaines; Madrid; Barcelona; Espagne

\section{Abstract. Residential dynamics of Latin American immigrants in the Barcelona and Madrid metropolitan areas: Trend changes during economic expansion, crisis and post-crisis periods}

This article examines the geographical settlement and migration patterns of the Latin American-born population in the functional urban areas of Barcelona and Madrid, Spain, from 2000 to 2017 . The municipalities of these areas have been grouped into several rings according to their distance to the central cities. Using data from local population registers (Padrón Continuo) and statistics on residential variations published by the Spanish National Statistics Institute (INE), the present research studies how these phenomena respond to economic cycles. For this reason, three periods of varying duration are studied: economic expansion (2000-2008), crisis (2009-2014) and post-crisis (2015-2017). The results show that the suburbanization of Latinos in both urban areas during the economic growth phase was halted by the crisis but reactivated during the post-crisis stage. Nevertheless, in recent years the Latino population has become increas- 
ingly concentrated in both central cities, as immigration flows from Latin American countries have reactivated once again.

Keywords: Latin American population; residential patterns; migration; metropolitan areas; Madrid; Barcelona; Spain

\section{Sumario}

\section{Introducción \\ 2. Antecedentes}

3. Áreas de estudio, fuentes estadísticas y criterios de análisis

4. Evolución de los stocks de población latinoamericana en las AUF analizadas
5. Las proporciones de población latinoamericana por coronas

6. Principales flujos de población latinoamericana

7. Discusión y conclusiones

Referencias bibliográficas

\section{Introducción}

España es el primer país europeo receptor de flujos migratorios latinoamericanos ${ }^{1}$ (Bayona et al., 2018: 12). A 1 de enero de 2017, la población de origen latinoamericano en España era de 2.419.842 personas, y correspondía al 5,2\% del total nacional y al 39,2\% del total de población nacida en el extranjero residente en el país ${ }^{2}$. Dentro de los múltiples factores que afectan a las migraciones, para este grupo de población ha sido la cercanía cultural, más que la geográfica, una de las razones que justifica su gran presencia en el país, aunque probablemente han tenido más importancia los aspectos políticos y económicos que se dan tanto en los lugares de origen como en España (Prieto y López-Gay, 2015; Hierro, 2016).

La intensidad de los flujos migratorios latinoamericanos hacia España también se ha visto afectada por las mayores facilidades que este grupo posee para la regularización de su condición legal de residencia y posterior reagrupación familiar en relación con otros destinos, como los Estados Unidos de Norteamérica u otros países con distintos idiomas (Domingo i Valls, 2005; Izquierdo et al., 2006), así como por las ventajas de las que disponen para la adquisición de la nacionalidad española, pues solo necesitan dos años de residencia legal para pedirla, a diferencia de los diez años que se exigen para otras nacionalidades (Gil-Alonso et al., 2012: 11).

El mayor influjo de migración latinoamericana residente actualmente en España se dio en los años del boom económico y migratorio, entre finales del siglo xx y el año 2008 (Martínez Buján, 2003; Urdiales-Viedma y FerrerRodríguez, 2005; Vicente-Torrado, 2006; López de Lera y Oso, 2007; García

1. En este artículo calificamos como latinoamericanos a las personas nacidas en cualquiera de los países del continente americano con lengua (co)oficial castellana o portuguesa.

2. Padrón continuo de población, resultados definitivos a 1 de enero de 2017. Fuente: Instituto Nacional de Estadística (INE) del Gobierno de España. 
Ballesteros et al., 2009; Gil-Alonso et al., 2012: 8). Con el estallido de la crisis económica en España, la inmigración latinoamericana cambió su comportamiento (Quintero, 2016; Bayona et al., 2017; Prieto et al., 2018). El número de entradas en España se redujo abruptamente mientras que aumentaron las salidas hacia el país de origen o hacia un tercer país. Los saldos migratorios pasaron de ser ampliamente positivos a negativos, si bien el stock de inmigrantes extranjeros se redujo menos de lo esperado. Los que provenían de algún país latinoamericano fueron los que más disminuyeron, aunque si analizamos estos contingentes en función del lugar de nacimiento y no de la nacionalidad, se observa que el descenso fue mucho menor, ya que muchos latinos adquirieron la nacionalidad española durante su estancia en España, a los que habría que sumar los nacidos en Latinoamérica que tenían la ciudadanía española previamente a su migración (Gil-Alonso et al., 2012: 15).

La recuperación de la economía española a partir de 2014 ha cambiado de nuevo la dirección de los flujos internacionales, que vuelven a mostrar un saldo positivo y con protagonismo, de nuevo, de la inmigración latinoamericana (Gil-Alonso y Thiers-Quintana, aceptado). Una serie de aspectos conjugados, en los que intervienen factores tanto económicos como políticos, son los que explican la evolución de los flujos recientes de procedencia latinoamericana y el aumento en los stocks de dicha procedencia; por ejemplo: las crisis políticas que están viviendo algunos países de origen, como es específicamente el caso de Venezuela y Brasil, o la agenda antiinmigratoria del actual gobierno estadounidense (Bayona et al., 2018).

Todos estos cambios en los flujos de entrada y salida de la población nacida en América Latina han tenido un impacto muy significativo en las áreas urbanas de Madrid y Barcelona, las dos mayores de España, y reconocidas como las principales receptoras de inmigración extranjera en general (Vázquez Varela, 2003; Bodega Fernández et al., 2006; Cebrián et al., 2008; Pozo Rivera y García Palomares, 2011; Bayona y Gil-Alonso, 2012; Bayona et al., 2011 y 2013; Pozo Rivera y Rodríguez Moya, 2018) y latinoamericana en particular, pues en ellas viven, en 2017, 1.060.065 nacidos en Latinoamérica, cerca del $44 \%$ del total residente en España. Los importantes cambios en los stocks de población latinoamericana han implicado, asimismo, un reajuste de los patrones migratorios y de movilidad residencial de este grupo, también en el interior de dichas áreas metropolitanas.

Es por ello que este artículo tiene como objetivo analizar, para las áreas urbanas funcionales de Madrid (AUFM) y de Barcelona (AUFB), los aspectos siguientes:

1. La evolución de los stocks de población latinoamericana y sus pautas residenciales — para ello se agruparán los municipios metropolitanos en una serie de coronas en función de la distancia a las ciudades centrales - entre los años 2000 y 2017.

2. Los cambios de residencia entre dichas coronas. Se prestará especial atención a las fluctuaciones en las distintas fases del ciclo económico. 
La hipótesis de partida respecto al primer objetivo es que, a pesar de las evidentes diferencias de tamaño y de conformación geográfica entre ambas metrópolis, la población latinoamericana ha seguido básicamente las mismas pautas de distribución geográfica en ellas, con predilección por una localización céntrica, que si bien se atenúa en la fase de expansión económica (2000-2008) debido a los flujos de suburbanización, se refuerza con la crisis económica (2009-2014) y se acentúa con la posterior recuperación en el periodo que ha sido calificado de «poscrisis» (2015-2017). Respecto al segundo objetivo, la hipótesis establece que los flujos migratorios intrametropolitanos de los inmigrantes latinos han cambiado de dirección también como consecuencia de la coyuntura económica, lo que ha afectado a las tendencias hacia la concentración o la dispersión urbana de dicho colectivo.

Tras repasar, a continuación, las investigaciones que han precedido y enmarcado este trabajo, el marco geográfico, las fuentes y la metodología utilizada, el artículo presenta la evolución de los stocks de población latinoamericana; su distribución entre las diversas coronas; los cambios residenciales entre ellas, y, finalmente, las principales conclusiones obtenidas como resultado del estudio.

\section{Antecedentes}

Los análisis acerca de la inmigración latinoamericana en España han dado progresivamente mayor visibilidad a la importancia de la inserción de esta población en la sociedad española, que se ha abordado desde diferentes ópticas. Entre los temas más investigados en artículos dedicados específicamente a este grupo, o junto a otros colectivos extranjeros, están los referidos a su participación en el mercado laboral, sus trayectorias migratorias o la construcción de redes migratorias (Gil-Alonso y Domingo, 2008; Vidal-Coso et al., 2008; Recaño y De Miguel, 2012; Prieto y López-Gay, 2015; Aysa-Lastra y Cachón, 2016).

Menos abordado ha sido, sin embargo, el tema que nos interesa en este artículo, el de sus pautas territoriales de residencia, particularmente en los principales ámbitos metropolitanos españoles (Vono de Vilhena y Bayona, 2010), más allá de la desmitificación de las concentraciones territoriales en forma de gueto ${ }^{3}$ y del análisis genérico de su movilidad residencial en comparación con otros grupos continentales (Bayona et al., 2011, 2013 y 2017; Quintero, 2016). Creemos que merece la pena realizar un análisis más detallado de estos aspectos por las implicaciones que la inserción residencial tiene en asuntos como la estructuración de las redes migratorias, la integración laboral, social y cultural de los inmigrantes, o también para la elaboración y el desarrollo de políticas públicas, tal como ha demostrado la ingente literatura internacional (véase, por ejemplo, Bélanger, 1993; Frey, 1995; Newbold, 1996; Rogers y Henning,

3. Los guetos (ghettos) son zonas con gran predominio de inmigrantes de un único origen étnico, que se ha demostrado que no existen en España (Sabater et al., 2013; Galeano et al., 2014). 
1999; Borjas, 2006; Zorlu y Latten, 2009). Particularmente interesante es el estudio de los comportamientos residenciales y migratorios de los inmigrantes extranjeros y la consiguiente conformación de tendencias de concentración o de dispersión en el espacio de dichos inmigrantes, como indicadores de mayor o menor integración en la sociedad de acogida, relación conflictiva que ha generado mucho debate teórico en las últimas décadas (Musterd, 2003).

Los antecedentes teóricos tanto justifican unas dinámicas de dispersión como de concentración. En cuanto al primer enfoque, la teoría de la asimilación diferencial (Massey y Denton, 1985) defiende que los inmigrantes nacidos en el extranjero se dispersan en el país de acogida desde los lugares de asentamiento iniciales, en los que se concentran los inmigrantes de un determinado grupo étnico o nacional hacia otras zonas con menor presencia de dichos inmigrantes ${ }^{4}$. Por el contrario, la teoría del enclave étnico propone que ciertos inmigrantes, incluso con éxito socioeconómico, pueden preferir permanecer en (o migrar a) zonas con elevadas proporciones de inmigrantes, donde obtienen beneficios de las redes sociales existentes (Damm, 2009), pudiéndose dar procesos de recentralización urbana. La literatura también justifica que dichas tendencias puedan ser opuestas en distintos grupos según su origen geográfico: es la teoría de la asimilación segmentada (Zhou y Portes, 2012), según la cual diversos grupos de inmigrantes se pueden integrar en el país de destino de diferentes maneras y a diversos ritmos.

En relación con la situación hallada en las principales áreas urbanas españolas —objetivo de este trabajo-, la bibliografía existente muestra que, aunque hasta la fecha no se han llegado a formar guetos (Sabater et al., 2013; Galeano et al., 2014), durante los años de fuerte e intenso crecimiento migratorio sí se fueron creando en las grandes urbes del país los denominados espacios de concentración, zonas donde la proporción de población inmigrante se encuentra por encima de la media del conjunto metropolitano y, por ende, del país. Estos espacios se han dado más entre algunos colectivos que entre otros, pues la tendencia a la segregación no es uniforme. Los africanos, pero sobre todo los asiáticos, y en menor medida también los europeos comunitarios, han destacado por su tendencia hacia la concentración, por lo que han resultado encontrarse en mayores niveles de segregación (Sabater et al., 2013), hasta el punto de que la presencia de porcentajes de extranjeros de determinados orígenes por encima de lo normal ha llegado a utilizarse como indicador de la propia vulnerabilidad de un barrio específico (Nel.lo et al., 2014).

Por el contrario, el colectivo latinoamericano ha sido el que ha mostrado, en la fase de expansión económica, la mayor tendencia hacia la descentralización y la dispersión y, por lo tanto, menor segregación (Bayona y Gil-Alonso, 2012: 320), en línea con la teoría de la asimilación diferencial. Sin embargo, las

4. Este proceso de dispersión para evitar residir en concentraciones étnicas es paralelo al avance socioeconómico de los inmigrantes y al fortalecimiento de los lazos que estos establecen con el país de acogida, e implica, desde el punto de vista de las dinámicas urbanas, una salida neta de extranjeros de los grandes centros urbanos. 
evidencias existentes en el interior de las áreas urbanas son escasas, puesto que la mayoría de los estudios que abordan la temática de la distribución espacial y la migración interna de los latinoamericanos lo hacen a escala provincial (Bayona et al., 2017; Gil-Alonso et al., 2012), de comunidades autónomas (Urdiales y Ferrer, 2005) o de la totalidad del país (Vicente, 2006). Además, hay pocos trabajos que analicen sus pautas residenciales y de movilidad urbana en la fase de crisis (Prieto et al., 2018; Quintero, 2016), y menos aún en la posterior etapa de poscrisis (Gil-Alonso y Thiers-Quintana, aceptado), periodos en los que la tendencia hacia la concentración del colectivo latinoamericano iría en contra de la teoría de la asimilación diferencial y a favor de la del enclave étnico. Es por ello que se plantea un estudio que supera el período del boom inmigratorio y que analiza también las dos fases posteriores para tratar así de obtener una visión más completa del fenómeno que permita analizar el comportamiento espacial de los latinoamericanos - y sus reacciones a la coyuntura económica - en las dos mayores áreas metropolitanas de España: Barcelona y Madrid.

\section{3. Áreas de estudio, fuentes estadísticas y criterios de análisis}

Las áreas urbanas de Madrid y Barcelona, principales puertas de entrada y distribución de la inmigración latinoamericana en España, se analizan a partir de la delimitación establecida en el marco del proyecto europeo Urban Audit iniciado a finales de la década de 1990, que tiene por objetivo comparar la calidad de vida en las principales ciudades europeas. Son las actualmente denominadas «áreas urbanas funcionales» (AUF), cada una de las cuales está conformada por una ciudad central y los municipios de su entorno funcional inmediato, definido en función de la influencia laboral 5 . Para el año 2015, las AUF de Madrid y Barcelona comprenden 166 y 135 municipios, respectivamente.

Estos ámbitos territoriales se han dividido en coronas de municipios según distancia radial entre el centro de Madrid y Barcelona y el centro de los restantes municipios de sus AUF, los cuales han sido agrupados en coronas cada 10 kilómetros de distancia. La figura 1 muestra dicha distribución de coronas en las dos áreas urbanas funcionales, mientras que la tabla 1 proporciona el número de municipios de cada corona y la población latinoamericana y total que reside en ellas en los años 2000, 2009, 2015 y 2017.

5. Una AUF es una agregación de unidades territoriales de ámbito local (municipios en el caso español) que se caracteriza por tener una parte significativa de su población ocupada residente que se desplaza a trabajar a la ciudad que da nombre al AUF. Así, un municipio pertenece al AUF de una ciudad si el 15\% o más de su población ocupada se desplaza a esa ciudad por motivos laborales. Para municipios de menos de 2.000 habitantes hay excepciones a la regla general y se utiliza la siguiente escala: de 1.000 a 2.000 habitantes, si el $25 \%$ de los ocupados se desplazan a la ciudad que da nombre al AUF; de 500 a 1.000 habitantes, el umbral es del 35\%; de 100 a 500, el umbral es del 45\%, y, finalmente, en los municipios de 0 a 100 habitantes, el umbral es del 50\%. Ese es el criterio principal, pero hay otros, como la contigüidad (INE: <https://www.ine.es/prensa/ua_2018.pdf>). 
Tabla 1. Distribución de municipios, población total y latinoamericana según coronas de distancias en las áreas urbanas funcionales de Barcelona y Madrid, a 1 de enero de los años 2000, 2009, 2015 y 2017

\begin{tabular}{|c|c|c|c|c|c|c|c|c|c|c|}
\hline \multirow[b]{2}{*}{ AUF } & \multirow[b]{2}{*}{ Distancia } & \multirow[b]{2}{*}{$\begin{array}{c}\mathrm{N} .{ }^{\circ} \\
\text { municipios }\end{array}$} & \multicolumn{2}{|r|}{2000} & \multicolumn{2}{|r|}{2009} & \multicolumn{2}{|r|}{2015} & \multicolumn{2}{|r|}{2017} \\
\hline & & & $\begin{array}{c}\text { Población } \\
\text { total }\end{array}$ & $\begin{array}{c}\text { Población } \\
\text { latinoamericana }\end{array}$ & $\begin{array}{c}\text { Población } \\
\text { total }\end{array}$ & $\begin{array}{c}\text { Población } \\
\text { latinoamericana }\end{array}$ & $\begin{array}{c}\text { Población } \\
\text { total }\end{array}$ & $\begin{array}{c}\text { Población } \\
\text { latinoamericana }\end{array}$ & $\begin{array}{c}\text { Población } \\
\text { total }\end{array}$ & $\begin{array}{c}\text { Población } \\
\text { latinoamericana }\end{array}$ \\
\hline \multirow[t]{8}{*}{ Barcelona } & Ciudad central & 1 & 1.496 .266 & 31.859 & 1.621 .537 & 173.902 & 1.604 .555 & 173.963 & 1.620 .809 & 188.450 \\
\hline & $<10 \mathrm{~km}$ & 9 & 831.584 & 7.782 & 874.703 & 87.580 & 865.500 & 86.394 & 874.889 & 92.711 \\
\hline & de 10 a $20 \mathrm{~km}$ & 38 & 932.776 & 7.762 & 1.106 .177 & 67.257 & 1.131 .213 & 62.953 & 1.140 .418 & 65.868 \\
\hline & de 20 a $30 \mathrm{~km}$ & 36 & 653.814 & 6.484 & 817.622 & 49.166 & 838.481 & 45.796 & 846.662 & 47.597 \\
\hline & de 30 a $40 \mathrm{~km}$ & 27 & 171.743 & 2.236 & 241.211 & 13.383 & 252.482 & 12.952 & 255.723 & 13.558 \\
\hline & de 40 a $50 \mathrm{~km}$ & 22 & 128.662 & 1.299 & 182.695 & 9.713 & 185.495 & 8.898 & 187.424 & 9.147 \\
\hline & $>$ de $50 \mathrm{~km}$ & 2 & 18.162 & 234 & 36.544 & 3.071 & 36.139 & 2.685 & 36.939 & 2.910 \\
\hline & Total & 135 & 4.233 .007 & 57.656 & 4.880 .489 & 404.072 & 4.913 .865 & 393.641 & 4.962 .864 & 420.241 \\
\hline \multirow[t]{8}{*}{ Madrid } & Ciudad central & 1 & 2.882 .860 & 142.967 & 3.255 .944 & 420.503 & 3.141 .991 & 377.669 & 3.182 .981 & 400.924 \\
\hline & $<10 \mathrm{~km}$ & 2 & 155.910 & 7.406 & 191.532 & 19.577 & 197.613 & 19.876 & 200.469 & 20.767 \\
\hline & de 10 a $20 \mathrm{~km}$ & 11 & 649.402 & 15.912 & 820.281 & 57.730 & 851.774 & 57.900 & 860.207 & 60.631 \\
\hline & de 20 a $30 \mathrm{~km}$ & 38 & 1.202 .699 & 26.707 & 1.598 .460 & 112.454 & 1.684 .434 & 109.834 & 1.696 .805 & 113.154 \\
\hline & de 30 a $40 \mathrm{~km}$ & 45 & 175.210 & 3.644 & 320.155 & 20.229 & 355.335 & 20.644 & 361.368 & 21.514 \\
\hline & de 40 a $50 \mathrm{~km}$ & 50 & 137.164 & 1.716 & 263.905 & 16.143 & 288.272 & 15.552 & 291.817 & 16.420 \\
\hline & $>$ de $50 \mathrm{~km}$ & 19 & 84.196 & 827 & 119.184 & 6.560 & 124.575 & 6.305 & 124.085 & 6.414 \\
\hline & Total & 166 & 5.287 .441 & 199.179 & 6.569 .461 & 653.196 & 6.643 .994 & 607.780 & 6.717 .732 & 639.824 \\
\hline
\end{tabular}

Fuente: elaboración propia a partir de los microdatos del Padrón continuo de población del INE referente a los años 2000 , 2009, 2015 y 2017.

Estos cuatro momentos dividen el periodo de 18 años analizado en tres etapas, marcadas por las inflexiones observadas en el análisis de los datos de flujos migratorios y que coinciden con las distintas fases económicas experimentadas en España durante dichos años: una primera fase de expansión económica y boom migratorio internacional, de 2000 a 2008; un segundo periodo de recesión económica, reducción de la inmigración y aumento de las salidas, de 2009 a 2014, y un tercer período, de 2015 a 2017, que se puede calificar de postcrisis, donde la incipiente recuperación económica viene acompañada por una recuperación de los flujos de entrada de inmigrantes internacionales.

$\mathrm{Al}$ analizar los resultados se han de tener en cuenta las importantes diferencias de extensión entre los dos municipios capitales, siendo que Barcelona posee una extensión de $102,76 \mathrm{~km}^{2}$, mientras que Madrid alcanza los $604,47 \mathrm{~km}^{2}$, así como las diferencias en la extensión de la totalidad de las AUF, que para la de Barcelona es de $2.628 \mathrm{~km}^{2}$ por los $7.876 \mathrm{~km}^{2}$ de la de Madrid'.

La fuente utilizada para estudiar las pautas residenciales de la población latinoamericana es el registro del Padrón continuo del Instituto Nacional de

6. También es relevante la disposición geográfica de ambas ciudades, puesto que Madrid está en el medio de un área similar a una circunferencia, mientras que la ciudad catalana centraliza una media circunferencia por su disposición de cara al Mediterráneo. 
Figura 1. Coronas de municipios según la distancia a la ciudad central

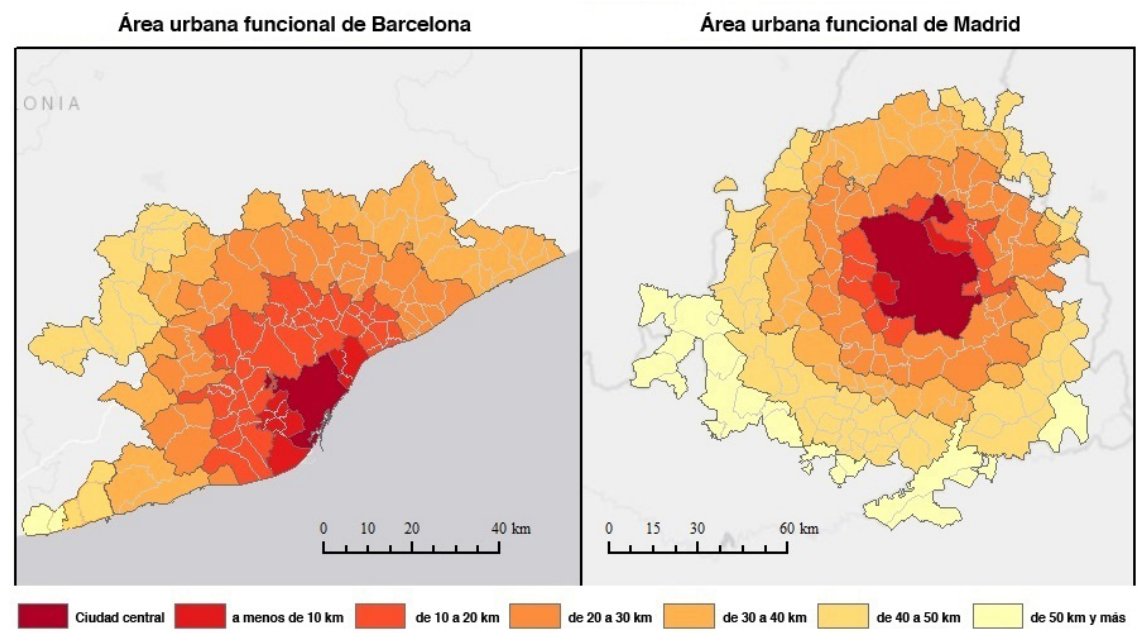

Fuente: elaboración propia sobre la base cartográfica del INE.

Estadística (INE), empleándose el criterio del país de nacimiento — y no de la nacionalidad - para evitar las distorsiones producidas por la adquisición de la nacionalidad española. Se obtienen así los stocks de población empadronada desde 2000 hasta 2017 en las dos ciudades y en cada una de sus coronas periféricas. Los flujos migratorios entre estas coronas, y entre ambas AUF y el exterior, se obtienen de los microdatos de la Estadística de variaciones residenciales (EVR) del INE, que informan sobre los cambios de domicilio (altas y bajas del padrón) en dichos ámbitos metropolitanos. La limitación de esta fuente es que no permite analizar la movilidad residencial intramunicipal —véase la excelente reflexión teórica sobre los conceptos de «movilidad residencial» y «migración» en Palomares-Linares et al. (2017) ${ }^{7}$ _, aunque para los fines de la presente investigación, centrada en el análisis de la variación anual de los stocks y los cambios de domicilio entre diversas coronas urbanas, la EVR cumple perfectamente esta función.

\section{Evolución de los stocks de población latinoamericana en las AUF analizadas}

La tabla 1 muestra cómo ha evolucionado la población nacida en Latinoamérica en las AUF de Barcelona y Madrid entre el 1 de enero de 2000 — cuando

7. Palomares-Linares et al. (2017) defiende que la «movilidad residencial» entendida en sentido estricto (cambio de domicilio dentro de un mismo ámbito metropolitano, independientemente de si este movimiento es intermunicipal o intramunicipal) solo puede medirse con el Censo de población. Sin embargo, la fecha del último censo (2011) y su realización a partir de una muestra no permiten que esta fuente sea útil para los objetivos de esta investigación. 
Figura 2. Crecimiento absoluto de la población latinoamericana por períodos y coronas de distancia a la ciudad central

$$
\text { Área urbana funcional de Barcelona }
$$

28.000

23.000

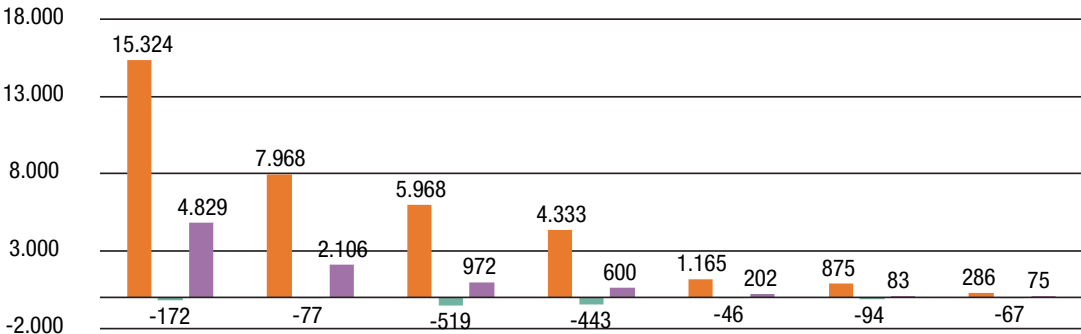

$-7.000$

Barcelona a menos de $10 \mathrm{~km}$ de 10 a $20 \mathrm{~km}$ de 20 a $30 \mathrm{~km}$ de $30 \mathrm{a} 40 \mathrm{~km}$ de $40 \mathrm{a} 50 \mathrm{~km}$ a más de $50 \mathrm{~km}$ ciudad central de Barcelona de Barcelona de Barcelona de Barcelona de Barcelona de Barcelona

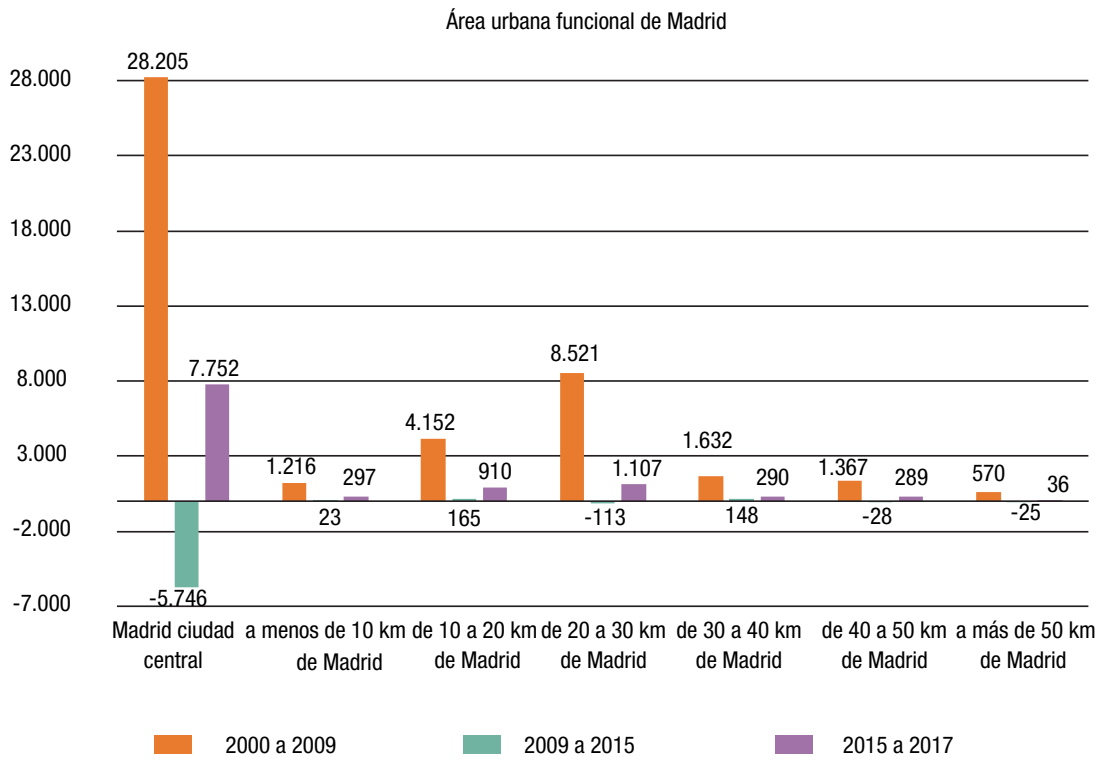

Fuente: elaboración propia a partir del Padrón continuo de población del INE correspondiente al período 2000-2017. 
residían 57.656 en la primera y 199.179 en la segunda- - 17 años después, cuando estas cifras alcanzan, respectivamente, 420.241 , o el 8,47\% de la población del AUFB, y 639.824, o el 9,52\% de la población del AUFM. Por lo tanto, el contingente latino es más importante en la urbe madrileña que en la catalana, tanto en números absolutos como en números relativos, aunque en esta última es donde más ha crecido desde el año 2000 (se ha multiplicado por 7, mientras que en el AUFM se ha triplicado), dado que partía de cifras inferiores.

El crecimiento experimentado no ha sido lineal, sino que ha mostrado distintas fases en función de la coyuntura económica. Así, ambas áreas muestran un fuerte crecimiento de la población de origen latino en la fase de expansión, un cierto retroceso durante la crisis - más significativo en la ciudad de Madrid-y un renovado incremento en la etapa de poscrisis, aunque este crecimiento es bastante menor que el que se dio en la primera etapa. En las tres fases, tanto el crecimiento como el decrecimiento son mayores en Madrid que en Barcelona en términos absolutos (aunque los resultados son distintos en números relativos, como se verá posteriormente).

El análisis por coronas del crecimiento absoluto de la población latinoamericana, para cada una de estas tres fases, muestra similitudes y diferencias entre ambas AUF (figura 2). Las dos ciudades centrales son las que muestran mayores incrementos en números absolutos en la primera fase de expansión (entre 2000 y 2008) y en la última de poscrisis (entre 2015 y 2017), pero luego aparecen diferentes patrones por coronas: mientras que en el AUFB los crecimientos son menores a medida que nos alejamos de la ciudad central, en el AUFM el mayor aumento de la población latina se observa en los municipios situados entre 20 y $30 \mathrm{~km}$, seguidos por los situados entre 10 y $20 \mathrm{~km}$.

Este reparto geográfico del incremento de la población latinoamericana en el AUF de Madrid responde al propio reparto de su población total, donde los municipios muy poblados situados entre 20 y $30 \mathrm{~km}$ (Getafe, Móstoles, Fuenlabrada, Torrejón de Ardoz y Alcalá de Henares, entre otros), seguidos por los situados entre 10 y $20 \mathrm{~km}$, tienen mucha más población que los situados más cerca de la ciudad de Madrid. Esto hace que la población inmigrante, y en particular la latina, sea más numerosa en estas dos coronas que en la más contigua a la capital, generándose así el denominado «efecto donut», como se puede comprobar en la tabla 1. Por el contrario, en el AUF de Barcelona este mayor peso demográfico se encuentra en las coronas $<10$ km (con ciudades como L'Hospitalet de Llobregat, Cornellà de Llobregat, Badalona y Santa Coloma de Gramenet) y 10-20 km (con 38 municipios y más de 1,1 millones de habitantes, entre ellos Sabadell, Sant Cugat del Vallès y otras muchas poblaciones de las populosas comarcas del Vallès Occidental y del Baix Llobregat).

Por lo tanto, los diferentes patrones geográficos existentes en ambas AUF en relación con las pautas residenciales de la población latinoamericana no responderían a un comportamiento espacial diferencial en ambas áreas urbanas, sino más bien al desigual reparto de la población total. Para demostrar esta 
Tabla 2. Tasa de crecimiento anual acumulativo (TCAA \%) de la población latinoamericana según las coronas de distancias en las áreas urbanas funcionales de Barcelona y Madrid

\begin{tabular}{|c|c|c|c|c|}
\hline AUF & & 2000-2009 & 2009-2015 & 2015-2017 \\
\hline \multirow[t]{8}{*}{ Barcelona } & Ciudad central & 20,75 & 0,01 & 4,08 \\
\hline & $<10 \mathrm{~km}$ & 30,86 & $-0,23$ & 3,59 \\
\hline & de 10 a $20 \mathrm{~km}$ & 27,11 & $-1,10$ & 2,29 \\
\hline & de 20 a $30 \mathrm{~km}$ & 25,24 & $-1,18$ & 1,95 \\
\hline & de 30 a $40 \mathrm{~km}$ & 22,00 & $-0,54$ & 2,31 \\
\hline & de 40 a $50 \mathrm{~km}$ & 25,05 & $-1,45$ & 1,39 \\
\hline & $>$ de $50 \mathrm{~km}$ & 33,12 & $-2,21$ & 4,11 \\
\hline & Total & 24,15 & $-0,43$ & 3,32 \\
\hline \multirow[t]{8}{*}{ Madrid } & Ciudad central & 12,74 & $-1,77$ & 3,03 \\
\hline & $<10 \mathrm{~km}$ & 11,41 & 0,25 & 2,22 \\
\hline & de 10 a $20 \mathrm{~km}$ & 15,39 & 0,05 & 2,33 \\
\hline & de 20 a $30 \mathrm{~km}$ & 17,32 & $-0,39$ & 1,50 \\
\hline & de 30 a $40 \mathrm{~km}$ & 20,98 & 0,34 & 2,09 \\
\hline & de 40 a $50 \mathrm{~km}$ & 28,28 & $-0,62$ & 2,75 \\
\hline & $>$ de $50 \mathrm{~km}$ & 25,87 & $-0,66$ & 0,86 \\
\hline & Total & 14,11 & $-1,19$ & 2,60 \\
\hline
\end{tabular}

Fuente: elaboración propia a partir de los microdatos del Padrón continuo de población del INE correspondientes a los años 2000, 2009, 2015 y 2017.

hipótesis hemos calculado el porcentaje de población latinoamericana respecto a la población total, por coronas, en ambas AUF para el año 2017. Partiendo de la ciudad central y hasta la corona $>50 \mathrm{~km}$, los porcentajes de latinos en el AUF de Barcelona son, respectivamente, 11,6\%, 10,6\%, 5,8\%, 5,6\%, 5,3\%, $4,9 \%$ y $7,9 \%$. En el caso del AUF de Madrid, 12,6\%, 10,4\%, 7,1\%, 6,7\%, $5,9 \%, 5,6 \%$ y 5,2\%. Las cifras de Madrid son, en general, un poco superiores, porque también el porcentaje de población latina respecto a la población total es mayor en su AUF (9,5\%) que en el de Barcelona (8,5\%), pero las pautas son muy similares, con mayor concentración de población latinoamericana a medida que nos acercamos al centro urbano ${ }^{8}$.

Dado que el crecimiento absoluto de la población latinoamericana está condicionado por el desigual tamaño de dicho contingente demográfico y de la población total en ambas áreas metropolitanas, es más relevante analizar el crecimiento o el decrecimiento de la población latina en las diferentes coronas en números relativos (tabla 2). De nuevo aparecen diferencias entre ambas urbes: durante la fase de expansión, en el AUF de Madrid las menores tasas de crecimiento de la población estudiada se dieron en la corona adyacente a la capital, seguida por esta, mientras que las mayores tasas se observaron en las dos coronas más exteriores (que partían de una población latina menor) segui-

8. La única ruptura de tendencia se produce en la corona $>50 \mathrm{~km}$ del AUFB, que incluye poca población y solo dos municipios costeros, por lo que es un caso aislado y poco significativo. 
das por las coronas entre 20 y $40 \mathrm{~km}$; por su parte, en el AUF de Barcelona, junto a los municipios situados a más de $50 \mathrm{~km}$, fueron los situados a menos de $10 \mathrm{~km}$ los que mostraron el mayor aumento, seguidos por aquellos entre 10 y $20 \mathrm{~km}$, lo que se puede interpretar como una expansión geográfica de los latinos a partir de la ciudad central hacia los municipios contiguos.

Posteriormente, en la fase de crisis, todas las coronas del AUF de Barcelona presentaron crecimiento negativo (el más acentuado fue la corona más exterior, seguida por la de 40 a $50 \mathrm{~km}$ ), con la única excepción de la ciudad de Barcelona, prácticamente estable, seguida por la corona contigua. Por el contrario, en el AUF de Madrid la ciudad central fue la que mostró la tasa más negativa, seguida por los municipios situados a más de $40 \mathrm{~km}$; mientras que las coronas $<10 \mathrm{~km}, 10-20 \mathrm{~km}$ y $30-40 \mathrm{~km}$ mostraron tasas de crecimiento pequeñas, pero positivas.

Finalmente, en la poscrisis, ambas AUF tienen en común que las dos ciudades centrales son las que más crecen (más Barcelona que Madrid), seguidas por las dos coronas adyacentes. Como diferencia, la corona $>50 \mathrm{~km}$ crece en el AUF de Barcelona tanto como la ciudad central, mientras que en el AUF de Madrid es la que crece menos.

En definitiva, mientras que en la fase de expansión y en la de crisis la población latina de ambas áreas mostraba comportamientos residenciales muy diferenciados - más centrípeto en el AUF de Barcelona, más centrífugo en el AUF de Madrid, con preferencia por los municipios entre 10 y $40 \mathrm{~km}$ («efecto donut») - , con la última fase, de poscrisis, parecen haberse igualado las pautas de la población latinoamericana en ambas metrópolis, pues aumentan sobre todo en las dos ciudades centrales, las que mejor y antes se han recuperado de la crisis, y en sus municipios más cercanos.

\section{Las proporciones de población latinoamericana por coronas}

Cuando observamos la evolución de la proporción de latinoamericanos por coronas respecto al stock total de los mismos en cada una de las AUF (figura 3), es posible ver que la ciudad central es más atractiva en ambos casos, aunque los niveles de concentración en las dos áreas sean diferentes.

Así, en el caso de Barcelona, la ciudad central concentraba, en el año 2000, el 55\% del total de latinoamericanos del AUF, que descendió hasta el $43 \%$ en 2009 debido a su expansión hacia las coronas adyacentes en los años del boom económico. Mientras, el porcentaje de latinos en 2000 y 2009 en las coronas $<10 \mathrm{~km}$ y $10-20 \mathrm{~km}$ pasó del $13,5 \%$ al $21,7 \%$ y también del 13,5\% al 16,6\%, respectivamente. La relativa recentralización durante los años de la crisis y la poscrisis hace que el porcentaje de población de origen latinoamericano que vive en la ciudad de Barcelona suba hasta el $45 \%$ en 2017, y hasta el $22 \%$ en la corona más cercana, mientras que disminuye hasta el $15,7 \%$ en la corona 10-20 km. También las coronas más periféricas pierden levemente proporción de latinos en 2017 respecto a 2009 y 2015, por lo que estos datos confirman la dinámica de concentración. 
Figura 3. Porcentaje de población latinoamericana por coronas sobre el total de población latinoamericana en las AUF de Barcelona y Madrid (2000-2017)

Área urbana funcional de Barcelona

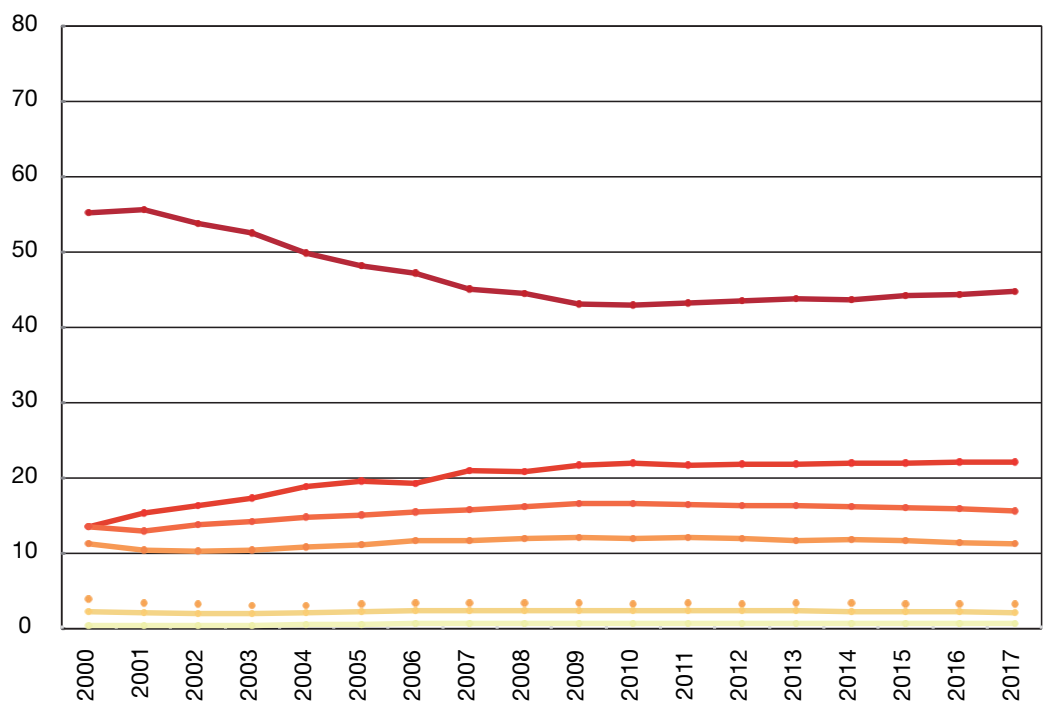

Área urbana funcional de Madrid

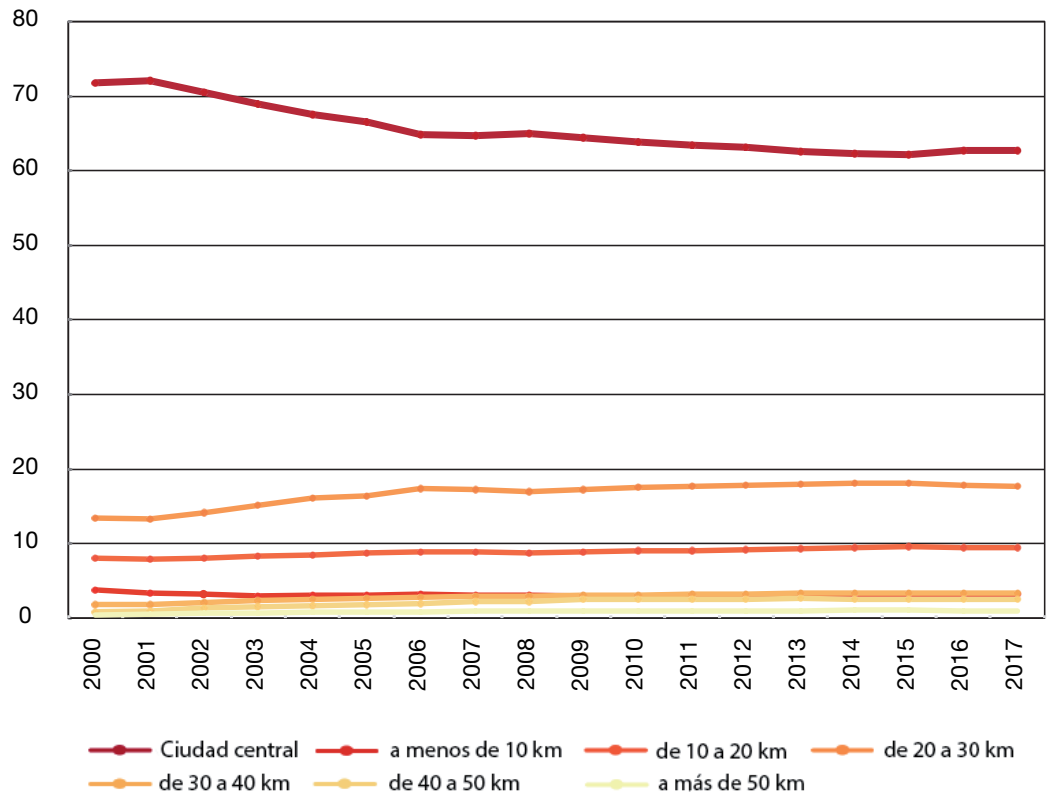

Fuente: elaboración propia a partir del Padrón continuo de población del INE correspondiente al período 2000-2017. 
Por su parte, la ciudad de Madrid concentra por encima del 70\% del total de latinoamericanos de su AUF en los años iniciales, para descender progresivamente a medida que se establece más población latina en las otras coronas. Así, el porcentaje de los que residen en la ciudad central disminuye al 64\% en 2009 y al 62\% en 2015, pues en la ciudad de Madrid, a diferencia de Barcelona, continuó disminuyendo el contingente latinoamericano durante los años de crisis. Con la recuperación económica se frena esta tendencia hacia la desconcentración de la población latinoamericana en el AUF de Madrid, y el porcentaje de los que residen en la ciudad central aumenta levemente hasta cerca del 63\%.

No obstante, cuando se compara la población latinoamericana que reside en las dos ciudades y en las distintas coronas periféricas, se ha de tener en cuenta la diferente extensión de los municipios de Barcelona y Madrid —este último es seis veces mayor y por lo tanto engloba mayor población-, lo que provoca que, en consecuencia, la corona $<10 \mathrm{~km}$ sea mucho mayor y más poblada en el AUF de Barcelona que en el de Madrid. Por esta razón, hemos decidido agrupar la ciudad central y la corona $<10 \mathrm{~km}$ para equiparar la comparación y, en ese caso, se observa un comportamiento muy similar entre ambas metrópolis.

En la catalana, la población latinoamericana que reside en estas dos coronas más céntricas pasa del 68\% del total en 2000 al 64\% en 2009, al 66\% en 2015 y al $67 \%$ en 2017 . En la madrileña, dichos porcentajes son el $75 \%$, el $67 \%$, el $65 \%$ y el 66\%, respectivamente. Por lo tanto, partiendo de una situación muy diferente en el año 2000 (más concentrada en Madrid que en Barcelona), se ha acabado con porcentajes muy similares en 2017.

Se observa, pues, una tendencia hacia la recentralización de esta población en el AUF de Barcelona desde el inicio de la crisis, mientras que en el AUF de Madrid esta tendencia es más reciente, desde el inicio de la recuperación económica.

Similarmente, también las coronas de 10 a $20 \mathrm{~km}$ y de 20 a $30 \mathrm{~km}$ —que, como vimos, tienen diferente peso demográfico en ambas metrópolis- aparentan dinámicas diversas en relación con el comportamiento residencial de los latinoamericanos, pero si se agrupan, para compensar el desigual tamaño y población, también aparecen pautas comunes. En el caso barcelonés, el porcentaje de población latina que reside en esas dos coronas pasa del $24 \%$ en 2000 al $29 \%$ en 2009 para disminuir al $28 \%$ en 2015 y al $27 \%$ en 2017 . En el AUF de Madrid los porcentajes respectivos son el 21\%, el 26\%, el 28\% y el $27 \%$. Es decir, de nuevo se parte de situaciones divergentes para acabar con porcentajes prácticamente iguales en ambas metrópolis, y otra vez el cambio de tendencia - hacia un menor peso del porcentaje de latinos que viven en estas coronas o, en otras palabras, hacia una menor desconcentración- se produce en 2009 en el AUF de Barcelona y en 2015 en el de Madrid.

\section{Principales flujos de población latinoamericana}

Esta tendencia centrípeta reciente de la población latinoamericana en las dos principales áreas urbanas españolas es menos evidente cuando se analizan los 
Figura 4. Evolución de los cambios de residencia realizados por población de origen latinoamericano en las AUF de Barcelona y Madrid (2000-2017)

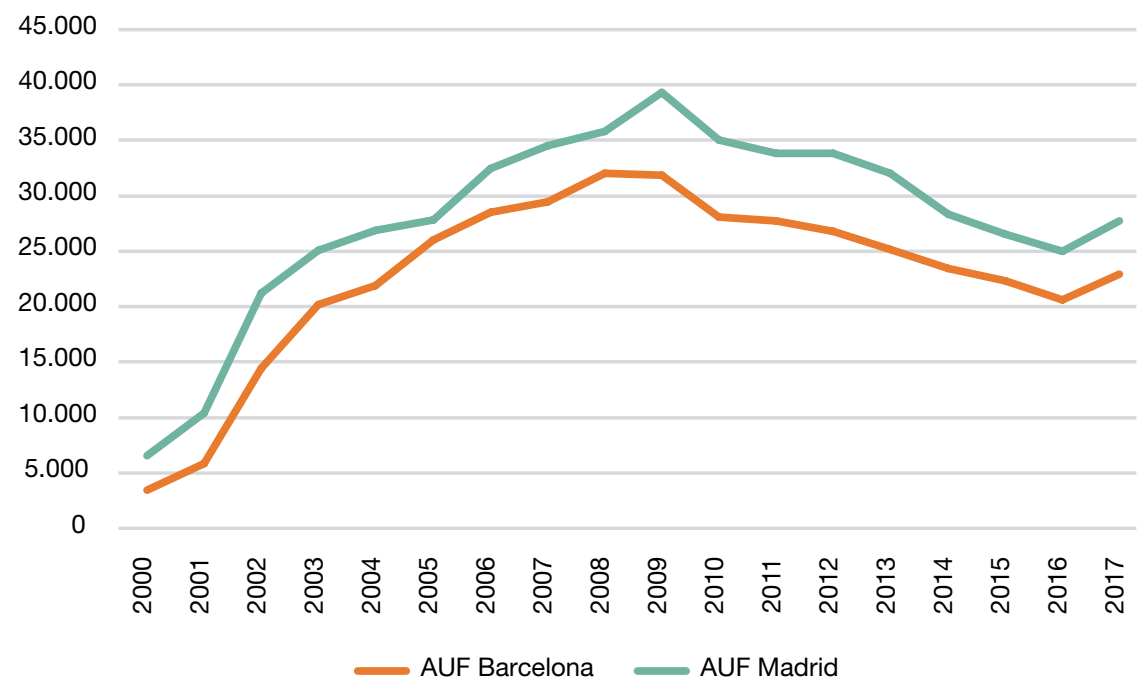

Fuente: elaboración propia a partir de las estadísticas de variaciones residenciales del INE correspondientes al período 2000-2017.

flujos migratorios intrametropolitanos protagonizados por este colectivo. Se ha de tener en cuenta, no obstante, que la evolución de los stocks en las diferentes coronas de Barcelona y Madrid depende tanto de la evolución de las migraciones internas como de las externas. Además, los migrantes que proceden directamente del extranjero suelen tener preferencia por un primer asentamiento en los grandes municipios, y en el caso específico de la migración de origen latinoamericano, las ciudades de Barcelona y, sobretodo, de Madrid actúan como puerta de entrada (Thiers et al., 2019) para, posteriormente, desplazar su residencia muchos de estos migrantes a municipios periféricos o del resto de España. Para analizar los diferentes flujos migratorios protagonizados por la población de origen hispanoamericano se ha utilizado la Estadística de variaciones residenciales (EVR) desde el año 2000 hasta el 2017, que corresponde a la secuencia de años con información a nivel municipal para los cuales se conoce el país de nacimiento de la población empadronada, pudiendo con ello identificar el grupo de origen continental que nos interesa? 9

La figura 4 muestra la evolución de los flujos migratorios internos de la población latinoamericana para ambas áreas funcionales estudiadas. Se observa

9. Se han seleccionado a aquellos nacidos en el continente americano, categoría que incluye, entre otros, a los nacidos en Estados Unidos y Canadá, aunque creemos que esto no interfiere en el objetivo de la investigación, pues solo comportan un $2 \%$ de la población nacida en América residente en España. 
que el número de cambios residenciales entre los distintos municipios de cada AUF es superior en la de Madrid, dado que concentra más población latinoamericana. Pero ambas áreas poseen el mismo comportamiento temporal, que responde (con 1 o 2 años de retraso) a las fases de la coyuntura económica: fuerte y constante aumento de los flujos de migración intrametropolitana desde el año 2000 hasta el 2008 en el AUFB y hasta el año 2009 en el AUFM, cuando se dan los máximos, y desde donde comienza también un descenso sostenido hasta 2016, para luego retomar el crecimiento en el último año registrado: 2017.

$\mathrm{Al}$ analizar estos cambios residenciales por coronas de distancia a la ciudad central - figura 5, que muestra las entradas (altas o inmigración), las salidas (bajas o emigración) y el saldo migratorio de la población de origen latinoamericano entre municipios de cada AUF-, se observa que la evolución de su intensidad varía según coronas, mostrando semejanzas y diferencias interesantes entre las áreas urbanas funcionales de Barcelona y Madrid.

La principal semejanza es que ambas ciudades centrales presentan un saldo migratorio negativo con el resto de municipios de sus AUF en la fase de expansión (suburbanización de la población latinoamericana), se produce un cambio de tendencia durante la crisis (recentralización) y se vuelve a activar la suburbanización en los últimos años.

También poseen un comportamiento parecido las coronas periféricas de ambas áreas, que es el opuesto al de la ciudad central, es decir, tienen un saldo migratorio muy positivo durante el boom económico e inmobiliario, un saldo negativo o cercano al equilibrio durante la crisis y de nuevo un saldo positivo - aunque, por ahora, menos pronunciado que en el periodo precrisis- en los últimos años.

Se diferencian ambas AUF, por ejemplo, en el desigual momento en el que el saldo migratorio cambia su signo - hacia el año 2010 en el AUFB y un par de años después en el AUFM-, debido a la menor y más tardía disminución de la inmigración latina en la capital española. De hecho, esta tiene un saldo migratorio interno de ciudadanos latinoamericanos muy positivo entre 2012 y 2015, lo cual no se da en la ciudad de Barcelona, donde durante los años de crisis el saldo es cercano a cero.

También es diferente el peso que tienen las diversas coronas en la magnitud de sus flujos de inmigración y emigración y, por lo tanto, de sus saldos migratorios, lo cual depende del volumen de población latinoamericana que reside en cada una de ellas. Así, la emigración a otros municipios del AUF de Barcelona principalmente la realiza, entre 2000 y 2008, la población residente en la ciudad central, pero a partir de 2009 es la corona situada a menos de 10 $\mathrm{km}$ de ella (principal receptora de inmigrantes latinos intrametropolitanos) quien pasa a ser la expulsora más importante. Este saldo negativo durará hasta el nuevo cambio de tendencia a partir de 2014.

Similarmente, en el AUF de Madrid es la corona de 20 a $30 \mathrm{~km}$ la que disputa el protagonismo a la propia ciudad de Madrid, tanto en inmigrantes latinos (de los cuales suele ser la principal zona de recepción) como en emi- 
Figura 5. Evolución anual de la migración interna (inmigrantes, emigrantes y saldo) de la población latinoamericana por coronas (2000-2017)

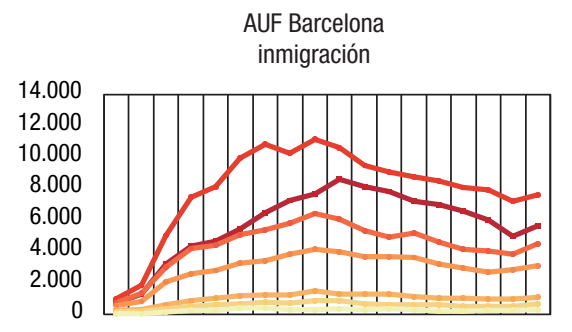

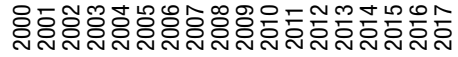

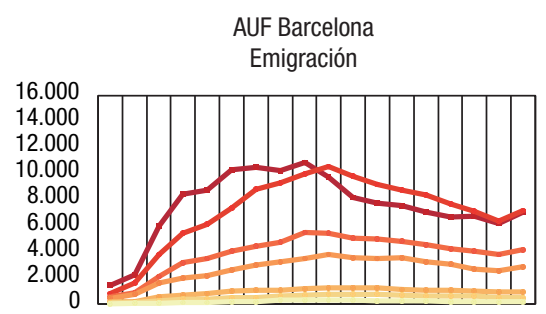

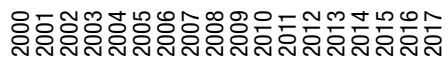

AUF Barcelona

Saldo migratorio

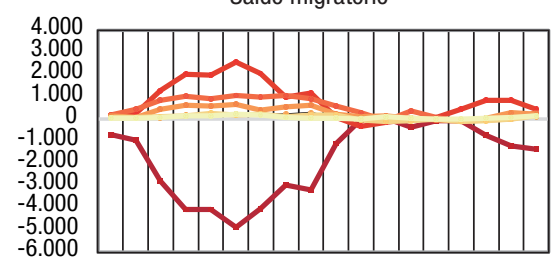

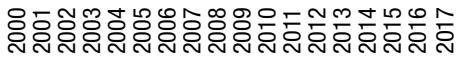

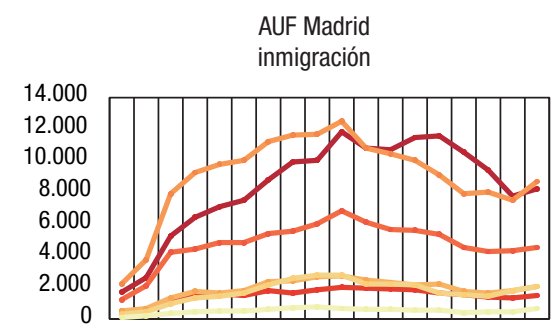

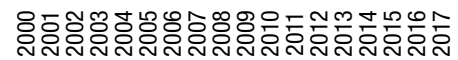

AUF Madrid

Emigración

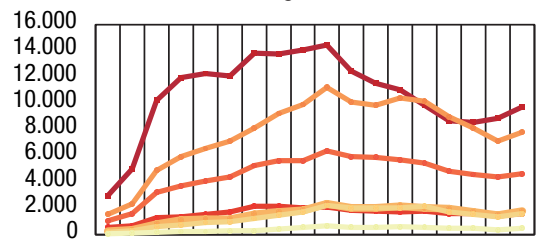

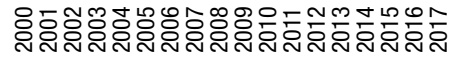

AUF Madrid

Saldo migratorio

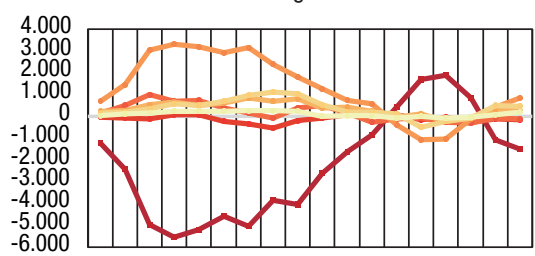

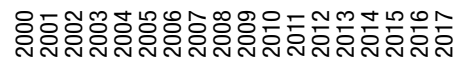
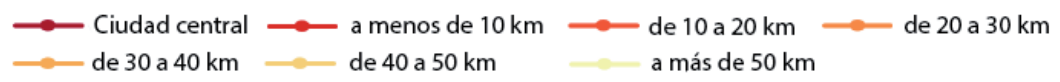

Fuente: elaboración propia a partir de la Estadística de variaciones residenciales del INE correspondiente al período 2000-2017.

grantes (segunda zona expulsora). También es esta corona la que protagoniza los principales cambios en el signo de los saldos, actuando como «espejo» de la ciudad de Madrid en las tres fases económicas.

Podemos concluir, por lo tanto, que la movilidad residencial interna de la población latinoamericana en las AUF de Madrid y Barcelona también responde a los avatares de la coyuntura económica: en las fases de crecimiento la población latina suele emigrar de los centros urbanos a la periferia, mientras 
Figura 6. Evolución anual del saldo migratorio externo entre las ciudades de Barcelona y Madrid y el resto de España y el exterior, para la población española, latinoamericana y total (2005-2016)

AUF Barcelona

Desde la ciudad central hasta el resto de España
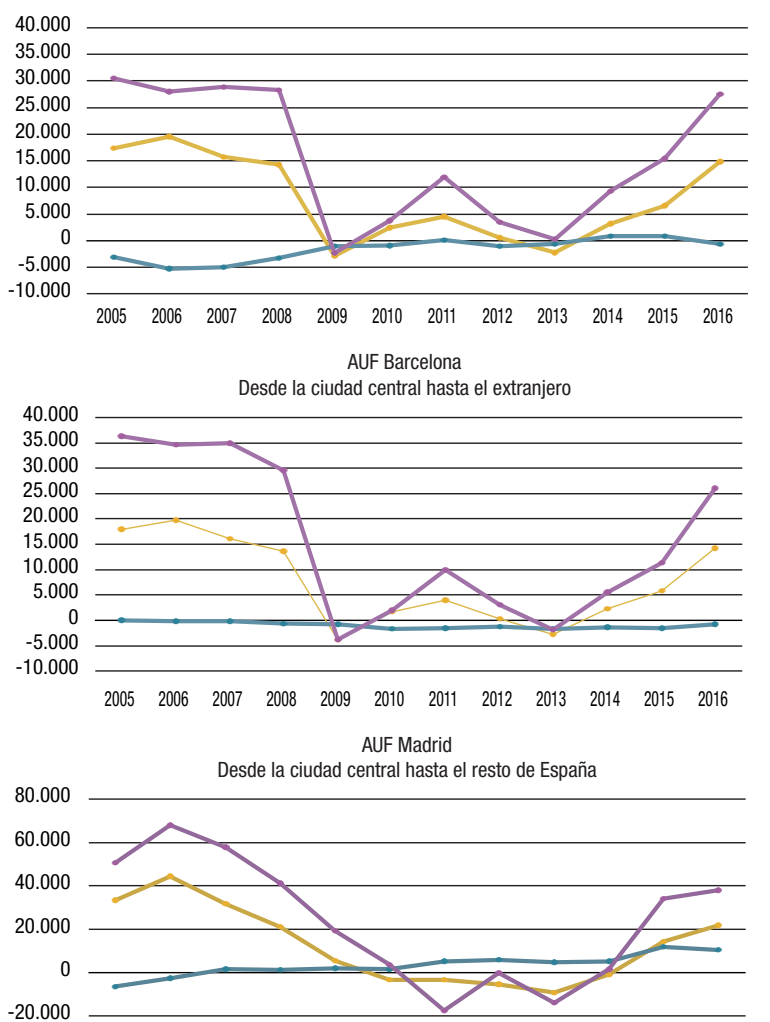

$-40.000$

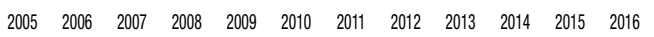

AUF Madrid

Desde la ciudad central hasta el extranjero

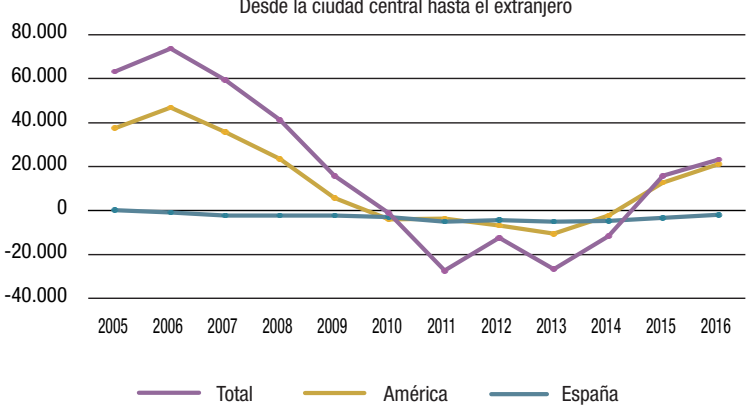

Fuente: elaboración propia a partir de la Estadística de variaciones residenciales del INE correspondiente al período 2005-2016. 
que en las fases de crisis se da el fenómeno contrario, lo que produce una tendencia hacia la recentralización. Este último fenómeno parece haber sido más acentuado en la ciudad de Madrid que en la de Barcelona, quizás porque en la primera - de mayor tamaño y extensión y con un parque residencial con mayor capacidad de expansión- el número de viviendas disponibles debe ser superior, particularmente en periodos de crisis donde la oferta supera a la demanda y los precios bajan; o quizás debido a que, como muestra la figura 6 , la magnitud de la emigración de población latinoamericana desde la ciudad de Madrid hacia el resto de España o hacia el extranjero ${ }^{10}$ — que no se dio en el caso de la ciudad de Barcelona- hizo aumentar dicho parque de viviendas disponibles. Este hecho pudo facilitar que latinoamericanos residentes en la periferia suburbana se pudieran establecer en Madrid durante los duros años de la crisis económica, con lo que redujeron el coste del transporte.

En suma, los flujos migratorios entre las dos AUF analizadas y el resto de España y el extranjero es lo que explica la aparente contradicción en la evolución entre flujos y stocks de población latinoamericana en los últimos años de poscrisis: si bien los flujos intrametropolitanos (figura 5) muestran una reactivación de la desconcentración, los stocks indican un mayor peso de la población latinoamericana en los dos municipios centrales, y ello es gracias a la reactivación de los flujos que proceden del exterior de ambas áreas urbanas (figura 6).

\section{Discusión y conclusiones}

Los resultados obtenidos en esta investigación han permitido confirmar las dos hipótesis de partida, a saber: que, a pesar de las evidentes diferencias de tamaño y de conformación geográfica entre ambas metrópolis, la población latinoamericana ha seguido básicamente las mismas pautas residenciales en las dos AUF, y que, también en ambas áreas urbanas, los flujos migratorios intrametropolitanos de los inmigrantes latinos han cambiado de dirección como consecuencia de la coyuntura económica, pasándose de una tendencia hacia la suburbanización en la fase de expansión económica (2000-2008) a una recentralización en la etapa de crisis económica (2009-2014) y, de nuevo, a una incipiente descentralización a medida que se asienta la posterior fase de recuperación económica en el periodo que ha sido calificado como "poscrisis» (2015-2017). Las tendencias hacia la dispersión durante las etapas de crecimiento económico estarían en línea con lo que explica la teoría de la

10. Utilizando los microdatos de la Estadística de variaciones residenciales (EVR), hemos calculado que entre 2010 — primer año en el que las salidas superaron a las entradas_ y 2014 la ciudad de Madrid tuvo un saldo negativo con el exterior de 27.220 latinoamericanos y un saldo negativo de 22.010 con el resto de España (excluidos los municipios del AUFM). Por el contrario, para los mismos años los saldos migratorios de la ciudad de Barcelona fueron positivos: 5.440 y 8.585 latinos, respectivamente. 
asimilación diferencial ${ }^{11}$ (Massey y Denton, 1985), mientras que la tendencia hacia la concentración en los lugares centrales durante la recesión respondería a una táctica defensiva frente a los impactos negativos de la crisis que se podría enmarcar en la teoría del enclave étnico (Damm, 2009). Este comportamiento diferencial incluso se podría relacionar con la teoría de la asimilación segmentada (Zhou y Portes, 2012) si se entiende esta de una manera amplia: no solo distintos grupos de migrantes se insertan en el territorio de diferente manera, sino que un mismo grupo puede variar su comportamiento territorial en varios momentos, en función de la coyuntura económica.

Existen, es cierto, algunas diferencias entre las dos áreas urbanas; por ejemplo: la mayor proporción de población latinoamericana en la ciudad de Madrid y en su corona de 20 a $30 \mathrm{~km}$, mientras que en el área barcelonesa los mayores porcentajes se encuentran en la Ciudad Condal y en las coronas que comprenden los municipios situados a menos de $10 \mathrm{~km}$ y entre 10 y $20 \mathrm{~km}$ de la urbe central. No obstante, la investigación ha demostrado que estas diferencias de localización espacial responden a la propia distribución geográfica de la población total en ambas AUF, de manera que, finalmente, el peso de la población latinoamericana es similar en las coronas de ambas áreas y tiene un gradiente decreciente, es decir, a medida que nos alejamos de la ciudad central, disminuye el porcentaje de población latina.

Esta querencia por una localización céntrica puede responder a varias causas relacionadas con las redes de transporte público - más densas en las zonas urbanas centrales (Bayona y Gil-Alonso, 2012; Thiers et al., 2017) —, la mayor disponibilidad de viviendas de alquiler en los centros urbanos (Rodríguez-López, 2007; Leal y Sorando, 2013; Azevedo et al., 2019) y el mercado laboral, entre otros factores. Sobre este último aspecto, es importante señalar que la mayor parte del colectivo latino - y especialmente las mujeres - se emplea en el sector servicios (Ribas Mateos, 2005; Gil-Alonso y Vidal-Coso, 2015), que ofrece mayor número y diversidad de puestos de trabajo en las grandes ciudades.

Otra diferencia es el más elevado peso inicial y actual de la población latina en el AUF de Madrid; sin embargo, los originarios de América Latina crecieron relativamente más en la fase de expansión y poscrisis y disminuyeron menos en la etapa de crisis en el AUF de Barcelona, por lo que, tras estos 17 años, la situación es más parecida en ambas áreas urbanas. De hecho, la ciudad de Barcelona no perdió habitantes de origen latino entre 2009 y 2015, mientras que la ciudad de Madrid perdió a más de 40.000 y todavía no había recuperado, a 1 de enero de 2017, los 420.503 que habían nacido en América Latina que residían

11. Durante la fase de poscrisis, el incremento de la población de origen latinoamericano en las ciudades centrales también se explicaría por la teoría de la asimilación diferencial, puesto que este crecimiento de los stocks latinos estaría siendo causado por el restablecimiento de los flujos de llegada desde sus países de origen, con preferencia por un asentamiento inicial en aquellos lugares donde ya había más latinos (las ciudades centrales). El simultáneo crecimiento de los flujos internos hacia los municipios periféricos estaría siendo protagonizado por aquellas personas de origen latinoamericano ya asentadas previamente y que se estarían periurbanizando. 
en dicha ciudad a 1 de enero de 2009 (tenía unos 20.000 menos). También el conjunto del AUFM contaba en 2017 con unos 45.000 latinoamericanos menos que ocho años antes, mientras que el AUFB solo tenía unos 10.000 menos.

Este comportamiento desigual parece indicar que la crisis afectó más duramente a la población latinoamericana residente en la ciudad de Madrid que en la de Barcelona, aunque algo menos en las coronas periféricas de la primera que en las de la segunda, de ahí que la ciudad de Barcelona fuera la única zona del AUFB que ganara algo de población latina entre 2009 y 2015, mientras que la ciudad de Madrid fue la zona de su área urbana funcional que más población latina perdió en dicho periodo (incluso hubo tres coronas periféricas con crecimientos ligeramente positivos).

Sin embargo, hemos visto también que la ciudad de Madrid mostró un significativo saldo positivo respecto al resto de coronas de su AUF en el periodo de crisis - lo cual no ocurrió en Barcelona-, y ello parecería estar en contradicción con lo que se acaba de decir. Sin embargo, los datos de la EVR han solucionado las dudas: la ciudad de Madrid tuvo un saldo negativo de población latinoamericana en relación con el resto de España y con el exterior de unos 50.000 habitantes, que no llegaron a compensar los latinos que emigraron de la periferia al centro. Por el contrario, la ciudad de Barcelona no tuvo ese significativo saldo positivo desde la periferia hasta el centro, pero tampoco perdió población latina hacia el resto de España o hacia el extranjero, sino que tuvo una pequeña ganancia que evitó que la población latinoamericana residente en la Ciudad Condal disminuyera durante el periodo de crisis. Por lo tanto, se podría afirmar que la población latinoamericana de Barcelona fue más resiliente a los embates de la crisis.

Finalmente, en los últimos dos años analizados, ambas ciudades y las restantes coronas de las dos AUF ganaron de nuevo población latina (más en el caso de las ciudades centrales y de las coronas más cercanas a estas que las más alejadas; y más Barcelona y su AUF que la urbe de Madrid y la suya). Este incremento de los latinos en las ciudades centrales - que ganan peso respecto a la población latina total - se da aunque se hayan restablecido los flujos de suburbanización hacia la periferia. Ello se debe a que, de nuevo, los saldos entre ambas ciudades centrales y el resto de España y el extranjero son favorables y crecientes. Esta reactivación de la inmigración latinoamericana es también mayor en Barcelona que en Madrid, quizás porque en el AUFB hay menos saturación de población de este origen $y$, por lo tanto, todavía mayor capacidad de crecimiento.

Se trata, sin embargo, de pequeños detalles que no enmascaran, en nuestra opinión, la gran semejanza de los patrones residenciales y de movilidad espacial de la población latinoamericana en las áreas urbanas de Barcelona y Madrid.

\section{Referencias bibliográficas}

Aysa-Lastra, María y Cachón, Lorenzo (2016). «Resistencia desde la vulnerabilidad: Inmigrantes latinos en España y Estados Unidos». En: Arango, J.; Mahia, R.; Moya, D. y Sánchez-Montijano, E. (dir.). El año de los refugiados: Anuario CIDOB de la Inmigración 2015-2016 (nueva época). Barcelona: CIDOB, 140-163. 
Azevedo, Alda Botelho; López-Colás, Julián y Módenes, Juan Antonio (2019). «Recent increase of tenancy in young Spanish couples: Sociodemographic factors and regional market dynamics». Journal of Housing and the Built Environment. <https:// doi.org/10.1007/s10901-019-09658-y>

Bayona-I-Carrasco, Jordi y Gil-Alonso, Fernando (20I2). «Suburbanisation and international immigration: The case of the Barcelona Metropolitan Region (19982009)». Tijdschrift voor Economische en Sociale Geografie, 103 (3), 312-329. <https://doi.org/10.1111/j.1467-9663.2011.00687.x>

Bayona-i-Carrasco, Jordi; Gil-Alonso, Fernando y Pujadas-i-Rúbies, Isabel (20II). "Dinàmica residencial de la població estrangera a les principals regions metropolitanes d'Espanya». Revista Catalana de Sociologia, 27, 15-32.

- (2013). «Migraciones intrametropolitanas de los extranjeros: Diferencias y semejanzas en las metrópolis de Barcelona y Madrid». Cuadernos de Geografía, 93, 27-5I.

Bayona-i-Carrasco, Jordi; Pujadas-I-Rúbies, Isabel y Ávila TÀpies, Rosalía (20I8). «Europa como nuevo destino de las migraciones latinoamericanas y caribeñas». Biblio 3W: Revista Bibliográfica de Geografía y Ciencias Sociales, XXIII (1242).

Bayona-i-Carrasco, Jordi; Thiers-Quintana, Jenniffer y Ávila Tàpies, Rosalía (2017). "Economic recession and the reverse of internal migration flows of Latin American immigrants in Spain». Journal of Ethic and Migration Studies, 43 (15), 2499-2518. <https://doi.org/10.1080/1369183X.2017.1296354>

BÉLANGER, Alain (1993). "La migration interprovinciale des personnes nées à l'étranger, Canada, 1981-1986». Cahiers Québécois de Démographie, 22 (1), 153-178. <https://doi.org/10.7202/010138ar>

Bodega Fernández, María Isabel; Cebrián de Miguel Juan Antonio y Matín Lou, María Asunción (2006). «El crecimiento de la población extranjera en Madrid: Un episodio característico de la inmigración internacional en la España del cambio de siglo». Estudios Geográficos, 67 (26I), 385-4I6.

BORJAS, George J. (2006). «Native internal migration and the labor market impact of immigration». Journal of Human Resources, 41 (2), 221-258. $<$ https://doi.org/10.3386/w11610>

Cebrián de Miguel Juan Antonio; Bodega Fernández, María Isabel; Martín Lou, María Asunción y El HarraK, Mariam (2008). «La inmigración extranjera en la región de Madrid». Geodemos, 9/10, 23-56.

Damm, Anna Piil (2009). "Ethnic enclaves and immigrant labor market outcomes: Quasi-experimental evidence». Journal of Labor Economics, 27 (2), 281-314. <https://doi.org/10.1086/599336>

Domingo i Valls, Andreu (2005). «Tras la retórica de la hispanidad: La migración latinoamericana en España entre la complementariedad y la exclusión». Papers de Demografia, 254, 1-23.

FreY, William H. (1995). "Immigration and internal migration "flight" from U.S. metropolitan areas: Toward a new demographic balkanization». Urban Studies, 32 (4-5), 733-757. <https://doi.org/10.1080/00420989550012861>

Galeano, Juan Martin; Sabater, Albert y Domingo, Andreu (2014). "Formació i evolució dels enclavaments ètnics a Catalunya abans i durant la crisi económica». Documents d'Anàlisi Geogràfica, 60 (2), 261-288. <https://doi.org/10.5565/rev/dag.111> 
García Ballesteros, Aurora; Jiménez Basco, Beatriz y Redondo GonzÁlez, Ángela (2009). "La inmigración latinoamericana en España en el siglo XXI». Investigaciones Geográficas, 70, 55-70. <http://dx.doi.org/10.14350/rig.18077>

Gil-Alonso, Fernando; Bayona-I-Carrasco, Jordi y Vono de Vilmena, Daniela (2012). "Las migraciones internas de los latinoamericanos en España: Del boom a la crisis económica». Papeles de Población, 18, 1-42.

Gil-Alonso, Fernando y Domingo, Andreu (2008). «Latinoamericanos en el mercado de trabajo español, 2000-2005». Papeles de Población, nueva época, 14 (55), 145-172.

Gil-Alonso, Fernando y Thiers-Quintana, Jenniffer (aceptado). «Population and economic cycles in the main Spanish urban areas: the migratory component». Comparative Population Studies.

Gil-Alonso, Fernando y Vidal-Coso, Elena (2015). «Inmigrantes extranjeros en el mercado de trabajo español: ¿Más resilientes o más vulnerables al impacto de la crisis?». Migraciones, 37 (junio), 97-123. <https://doi.org/10.14422/mig.i37.y2015.005>

Hierro, María (20I6). «Latin American migration to Spain: Main reasons and future perspectives». International Migration, 54 (I), 64-83. <https://doi.org/10.1111/imig.12056>

Izquierdo Escribano, Antonio; López de Lera, Diego y Martínez Buján, Raquel (2006). «Los preferidos del siglo xxi: La inmigración latinoamericana en España». En: Canales, A. Panorama actual de las migraciones en América Latina: Asociación Latinoamericana de Población. Guadalajara, México: Universidad de Guadalajara.

Leal Maldonado, Jesús y Sorando Ortín, Daniel (2013). «Rehabilitación urbana y cambio social en las grandes ciudades españolas». Revista Aragonesa de Administración Pública, 15, 205-236.

López de Lera, Diego y Oso, Laura (2007). «La inmigración latinoamericana en España. Tendencias y estado de la cuestión». En: Yépez del Castillo, I. y HerreRA, G. (eds.). Nuevas migraciones latinoamericanas a Europa: Balances y desafios. Quito (Ecuador): FLACSO-OBREAL-UCL-UB, 31-67.

MaRTínez Buján, Raquel (2003). La reciente inmigración latinoamericana a España Santiago de Chile: CELADE - División de Población. Serie Población y Desarrollo, 40 .

Massey, Douglas S. y Denton, Nancy A. (1985). «Spatial assimilation as a socioeconomic outcome». American Sociological Review, 50 (1), 94-106. <https://doi.org/10.2307/2095343>

Musterd, Sako (2003). «Segregation and integration: A contested relationship». Journal of Ethnic and Migration Studies, 29 (4), 623-641. <https://doi.org/10.1080/1369183032000123422>

Nel-Lo, Oriol; Jiménez, Eduard; Donat, Carles y Gràcia, Javier (2014). Evolució de la segregació a Catalunya, 2001-2012. Volumen I. Presentació i resultats preliminars. Bellaterra: IGOP. Universitat Autònoma de Barcelona.

Newbold, K. Bruce (1996). "Internal migration of the foreign-born in Canada». International Migration Review, 30 (3), 728-747. <https://doi.org/10.1177/019791839603000304>

Palomares-Linares, Isabel; Feria, José María y Susino, Joaquín (20I7). «Medida y evolución de la movilidad residencial en las áreas metropolitanas españolas». Papers: Revista de Sociologia, 102 (4), 545-574. 
Pozo Rivera, Enrique y García Palomares, Juan Carlos (2011). «Evolución reciente y pautas de distribución espacial de las migraciones internas de extranjeros: El caso de la Comunidad de Madrid (1997-2008)». Scripta Nova: Revista Electrónica de Geografía y Ciencias Sociales, XV (384).

Pozo Rivera, Enrique y Rodríguez Moya, Juana M.a (2018). «Impacto de la crisis en los movimientos migratorios en la Comunidad de Madrid (2007-2013)». Boletin de la Asociación de Geógrafos Españoles, 77, 229-255.

Prieto, Victoria y López-Gay, Antonio (2015). "Push and pull factors of Latin American Migration to Spain». En: Domingo, A.; Sabater, A.; Verdugo, R. (eds.). Demographic Analysis of Latin American Immigrants in Spain: From boom to bust. Suiza: Springer International, 1-28.

Prieto, Victoria; Recaño, Joaquín y Quintero-Lesmes, Doris (2018). «Migration responses of immigrants in Spain during the great recession». Demographic Research, 38 (61), 1885-1932.

Quintero Lesmes, Doris Cristina (2016). «Transformaciones territoriales de las migraciones internas de los latinoamericanos en España en tiempos de crisis económica». Scripta Nova: Revista Electrónica de Geografia y Ciencias Sociales, XX (549-3).

Recaño, Joaquín y De Miguel, Verónica (20I2). «The Internal Migration of ForeignBorn Population in Southern Europe: Demographic Patterns and Individual Determinants». En: Finney, N. y Catney, G. (eds.). Minority Internal Migration in Europe. Surrey: Ashgate Publishing. International Population Studies Series, 239-262. <https://doi.org/10.4324/9781315595528>

Ribas Mateos, Natalia (2005). «Todo por la familia: La emigración de las mujeres desde el origen». En: Checa y Olmos, Francisco (coord.). Mujeres en el camino: El fenómeno de la migración femenina en España. Barcelona: Icaria, 105-116.

Rodríguez-López, Julio (2007). «Urbanismo, vivienda y economía en España». ACE: Architecture, City and Environment, 1 (3), 80-85.

Rogers, Andrei y Henning, Sabine (1999). "The internal migration patterns of the foreign-born and native-born populations in the United States: 1975-80 and 1985-90». International Migration Review, 33 (2), 403-429. <https://doi.org/Io.II77/or979I839903300205>

Sabater, Albert; Galeano, Juan y Domingo, Andreu (20I3). "La transformación de las comunidades mayoritarias y la evolución de los enclaves étnicos residenciales en España». Migraciones, 33, II-44.

Thiers-Quintana, Jenniffer; Bayona-I-Carrasco, Jordi y Pujadas Rúbies, Isabel (2017). «Espacios de concentración de latinoamericanos en el Área Metropolitana de Barcelona: Un análisis de sus dinámicas recientes». Cuadernos Geográficos, 56 (3), 228-246. Recuperado de <http://revistaseug.ugr.es/index.php/cuadgeo/article/ view/5276>.

Thiers-Quintana, Jenniffer; Pujadas Rúbies, Isabel y Bayona-i-Carrasco, Jordi (2019). «Movilidad residencial, concentración territorial y características sociodemográficas de los latinoamericanos en las metrópolis de Madrid y Barcelona». Biblio 3W: Revista Bibliográfica de Geografía y Ciencias Sociales. Barcelona: Universitat de Barcelona, 24 (1.272) (25 de mayo).

Urdiales Viedma, María Eugenia y Ferrer Rodríguez, Amparo (2005) «La inmigración latinoamericana en España». Anales de Geografía, 25, 115-134. Recuperado de <http://revistas.ucm.es/index.php/AGUC/article/view/AGUC0505110115A>.

VÁzquez VArela, Carmen (2003). «Inmigración extranjera y renta familiar disponible en la Comunidad de Madrid: Pautas de localización y relaciones espaciales». En: 
Moreno, Antonio (coord.). La distribución espacial de la renta en la Comunidad de Madrid. Madrid: Instituto de Estadística. Comunidad de Madrid.

Vicente-Torrado, Trinidad L. (2006). «La inmigración latinoamericana en España». Expert group meeting on international migration and development in Latin America and the Caribbean. Population Division. Department of Economic and Social Affairs, United Nations Secretariat Mexico City. Del 30 de noviembre al 2 de diciembre de 2005.

Vidal-Coso, Elena; Gil-Alonso, Fernando y Domingo, Andreu (2008). «La distribución territorial de la población femenina extracomunitaria en España: Factores demográficos y laborales». Papeles de Geografía, 47-48, 193-213.

Vono de Vilhena, Daniela y Bayona-I-Carrasco, Jordi (2010). «El asentamiento residencial de los latinoamericanos en las principales ciudades españolas (20012009)». Notas de Población, 91, 129-159.

Zhou, Min y Portes, Alejandro (2012). «The new second generation: Segmented assimilation and its variants». En: Sú́rez-Orozco, C. et al. (eds.). The New Immigration. Routledge, 99-116. <https://doi.org/10.1177/0002716293530001006>

Zorlu, Aslan y LatTen, Jan (2009). "Ethnic Sorting in the Netherlands». Urban Studies, 46 (9), 1899-1923.

<https://doi.org/10.1177/0042098009106023> 